Instructions for authors, subscriptions and further details:

http://ijep.hipatiapress.com

\title{
Understanding Children in Foster Care: Identifying and Addressing What Children Learn from Maltreatment
}

María Gracia Peñarrubia Sánchez ${ }^{1}$

1) Universidad Loyola Andalucía, Spain.

Date of publication: February $24^{\text {th }}, 2018$

Edition period: February 2018 - June 2018

To cite this article: Peñarrubia Sánchez, M. G. (2018). [Book Review of Understanding children in foster care: Identifying and addressing what children learn from maltreatment by W. Kelly] International Journal of Educational Psychology, 7(1), 90-92. doi: 10.17583/ijep.2018.3197

To link this article: http://dx.doi.org/10.17583/ijep.2018.3197

\section{PLEASE SCROLL DOWN FOR ARTICLE}

The terms and conditions of use are related to the Open Journal System and to Creative Commons Attribution License (CC-BY). 


\section{Review}

Kelly, W. (2017). Understanding children in foster care: Identifying and addressing what children learn from maltreatment. Wellington: Palgrave MacMillan.

Children in the protection system is one of the most vulnerable groups in society. These children have typically experienced maltreatment, parental substance abuse or mental health issues, poverty and separation from their families. Although child protection policies are different in each country (in the UK and USA family care is more frequent, but in Spain still prevails residential care), children in care have been usually exposed to several risk factors, including traumatic experiences, disruption of attachment bonds and lack of expectable environments in which the child interacts with others and has sufficient stimulation of the senses.

In the first half of the book, Wendy Kelly provides context in a theoretical discourse on the psychological and attachment difficulties for children in care, including a discussion of maltreatment and foster care. She presents a very complete review focused on the mental health problems that children in care frequently present, but also attachment disturbances and abnormalities in brain functioning. A relevant factor she points out is that children's mental health problems are related to the length of time they spend in the adverse environment, as well as the extent of the maltreatment. This is an important information in order to stablish policies to remove children from abusive and neglectful homes.

With a clear style, Kelly states the behavioural difficulties and barriers that children with complex experiences of maltreatment and trauma can present in their new settlement, showing resistant and unpredictable behaviour towards their new caregivers. She emphasizes in different sections of the book how important is to maintain the vision of the uniqueness of 
every child's experiences, keeping in mind how their early life adversities have impacted their internal working models of attachment and their current behaviour. Foster care families provide a stable and safe environment for these children, building a supportive and nurturing relationship with the child that is vital to the child's recovery from maltreatment.

In the second part of this book, Kelly introduces the Relational Learning Framework (RLF), an assessment tool derived from her clinical experience to help caregivers to understand and respond empathically to the challenging behaviour presented by these children. RLF assists foster parents, social workers and mental health clinicians to examine what children who have experienced abuse and neglect learn from these experiences about relationships. This tool, grounded in attachment theory, moves the focus from behaviour problems and conflict to the child's perspective, considering the child's current internal working model of relationships to show them another model of how people can be together and how a family works.

The RLF process is based in five steps: review of the child's history and culture, problems and strengths, view of self, view of the others and the world, and what the child needs to learn from relationships. Steps three and four are a visual representation of the child's internal working model, derived from the two first steps; the final goal is design interventions to help parents to provide a secure base for the child's healing and recovery and changing the child's internal working model.

RLF is a method of case conceptualisation, which is not usually subject to empirical study. However, two pilot studies were conducted by the author to evaluate the tool, framed in a psycho-education training program. The intervention showed significant positive effects for children's daily problem behaviour, parent daily stress, overall emotional and behaviour problems (Kelly, 2015), demonstrating promising results for this tool. As a methodology, Kelly uses a variety of practical cases to exemplify and train the RLF including extended case studies, a deeper insight into the complex information about child's experiences, behaviour management for foster parents and trouble shooting.

This book is a highly valuable source for clinical practitioners, social workers and foster parents who want to deepen the complex information about children in foster care to improve their relationships. Furthermore, it 
72 Peñarrubia Sánchez - Children in Foster Care [Book Review]

will also provide insight into children in other protection measures, like residential and kinship care and adoption.

\section{References}

Kelly, W. J. (2015). Foster parents' understanding of the foster child's perspective: Does it matter, and can it be changed? (Doctoral dissertation). Retrieved from http://researcharchive.vuw.ac.nz/xmlui/handle/10063/4684

María Gracia Peñarrubia Sánchez Department of Psychology Universidad Loyola Andalucía mgpenarrubia@uloyola.es 